\title{
The Impact of Risk Attitude on the Network Purchasing Decision
}

\author{
Xiaolin Zhu \\ Liberal Arts and Sciences Faculty, Shanghai Second Polytechnic University, Shanghai, 201209, \\ China \\ 845337951@qq.com
}

Keywords: Risk attitude, Network purchasing decision, Risk seeking, Risk reversion.

Abstract. Three hundred university students were randomly selected as participants. In order to explore that whether different risk attitude have effect on the network purchasing decision. They were conducted a questionnaire survey including risk attitude and network purchasing decision. The result reflects that: the personal risk attitude significantly influenced the network purchasing decision.

\section{Introduction}

Decision making is an important aspect of human life, and human life is the result of decision. How to make judgments or decisions on different issues, and how to make decisions is a topic which has been concerned by different researchers. The research of related theory has played a more and more important role in people's realistic decision. Simon (A.simon Herbert, 1947) made economics research into psychology research methods. Decision making is a procedure, a process of finding problems, analyzing problems, the subjective probability of the event. Decision making, in the process of decision making under uncertain events are more restricted to decision-making.

Nowadays, more and more people begin to choose the network shopping, which is a network consumer army. According to reports, in November 11, 2012, the online shopping platform of Taobao lynx mall held a double eleven activities and transactions amounted to 191 hundred million yuan in a day. As we all know, there is a big difference between the network shopping and traditional shopping channels, including the risk of shopping, logistics and payment. Tan (1999) proved that consumers in online shopping perceiving risk is significantly higher than in store, and consumers of online shopping perceiving risk is higher. Different risk attitude of consumers in online shopping decision-making has a difference? After "Double 11", many people shouted their excess consumption, and bought a lot of unnecessary things. How to avoid unnecessary consumption so as to achieve the rational consumption?

Purchase decision is the consumer as the main body to meet the needs of this specific target in the purchase process of evaluation, selection, judgment, decision, and a series of activities. Purchase decision-making is a typical aspect of decision-making, and is a hot issue in the field of consumer research. Hawkins.Dell (2001) pointed out that the purchase decision is a careful evaluation of a product, service or brand attributes and make rational choice. That is, the consumer really use their own perception, attention, memory, thinking and other cognitive ability, to cause the need to gather information, and determine the purchase. The post purchase behavior have five stages (Robert, Donovan), including the length of the consumer demand, the level of commodity understanding and understanding of goods understanding and understanding of the goods, Cognitive level, pre purchase readiness status, and personality characteristics (Luo Ziming, 2002).

Network purchase decision-making is based on the electronic commerce mode of the purchase decision, and mainly on the network of goods for evaluation, selection, judgment and decision. Some researchers consider whether consumers are buying behavior as the criteria for decision making, while others believe that consumer decision not only refers to the purchasing behavior, but also a part of the decision making.

Chen and Ma (2012) have proved that the factors affecting the network purchase decision-making in e-commerce are consumer characteristics, product characteristics and risk perception, etc. Jarvenpa (1999) concluded that the consumer's attitude and perceived risk have significant impact on online 
purchase intention. Wang (2008) and Zhang (2006) also confirmed that the personality characteristics affected consumer decision-making style. Although the network purchase decision of the subject in the domestic academic community has attracted attention, this research is not enough. The research focus is on the management of the subject and the research object is mostly electronic business model of consumer purchase decision. The impact factor of the network purchase decision-making, and more research on the interface, business, environment, the purpose is to improve the e-commerce shopping environment, e-commerce website design and online marketing strategy formulation (Chen, 2008; Chen \& $\mathrm{Li}, 2007)$. In the research of network purchase decision-making, the research of psychology is little, and the influence of risk attitude has not been studied. In addition, in the research of network purchase decision-making is mostly on the process of decision-making. As the research variables, the psychological variables were included in this study as the main research variables, and the psychological characteristics of the network purchase decision factors were studied. The effect of the factors and the content of the subjects were discarded.

\section{Method}

\section{The experimental study on the availability of a network purchase scenario}

\section{Purpose}

The establishment of the network can be used for the purchase of experiments.

Test

40 university students were random selected. A total of 40 questionnaires were issued and the actual recovery of 40 copies. The subjects were free to participate in the experiment.

Experimental materials

According to consumers of different categories of online shopping perceived risk research of Li (2008)and online shopping risk sources of Yu (2007), we designed online purchase scenarios so as to determine the risk and make a decision whether to buy.

Experiment program

Experiments were carried out in a quiet scene and in a separate experiment without any outside interference, and subjects were asked to answer the question, then the subjects were interviewed to determine the risk factors in the situation.

Results

The results showed that 37 of the online purchase scenarios were considered to have risk, and 27 subjects made the decision, and the results showed that the trial was not to buy because of the risk in the situation, so it can be proved that the establishment of the network can be used to buy.

\section{The effect of risk attitude on the network purchase decision}

Subject

Undergraduate students were randomly selected to be tested. A total of 300 questionnaires were issued, and 296 were recovered, of which 6 were invalid questionnaires. 77 males and 213 females were included in subjects. They were volunteered to participate in the experiment and after the end of the experiment a gift was given to subject.

Experimental materials

Risk attitude questionnaire

The contents of several aspects of risk attitude were developed by Weber et al in 2002 and revised the domain specific risk scale used five point scoring, from 1 (very unlikely) to 5 (very likely).A total of 40 topics include financial, health, safety, entertainment, ethics and social policy. Internal consistency coefficient of the scale was between $0.71-0.86$, with good convergent validity and structure validity. Individual scale score is higher than the average count standard poor risk seekers, below the average standard difference for the risk averse, scoring in between the two risks neutral.

Online purchase decision situation questionnaire

According to consumer products in different categories of online shopping perceived risk research of $\mathrm{Li}$ (2008) and online shopping risk sources of $\mathrm{Yu}$ (2007), the measurement tool of network shopping 
decision-making was developed and included types and effects of factors of network purchase situation. The products are divided into the theory of search products, experience products, trust products, consumers of the three the perceived risk is gradually increased, consumers must experience goods in order to make a proper judgment on the quality of products in use, in the context of products in accordance with the definition of experience goods. The studies have shown that online shopping will have delivery risk, exchange risk, payment risk and information reliability risk so, based on the above information, and designed 2 purchase scenarios. Subjects of purchase intention are subject to make a purchase decision, and no purchase intention is not to make subjects to purchase decision.

Positive and Negative Affect Schedule(PANAS):

The Chinese version of 10-item Negative Affect (NA) scale of the Positive and NegativeAffect Schedule (PANAS; Watson, Clark, \&Tellegen,1988) was used to measure the negative affectivity of participants. Participants ratedtheir feelings for eachnegative affect item (e.g., "distressed," "upset," "nervous," "afraid") based on 5-point Likert-type scale ranging from 1 (veryslightly or no) to 5 (extremely). Higher overall scoreson the PANAS-NA are indicative of higher negative affectivity. Zhange and colleagues have reported that the internal consistency of this Chinese version of PANAS is 0.87 , which indicates that the result of this scale has high reliability and validity

\section{Experimental design}

A single factor (risk attitude: risk seeking, risk neutral, risk aversion) completely randomized experimental design was adopted. As a result of the result of the purchase decision of the network, whether to produce the purchase intention was to measure the result of the decision.

Experimental procedure

Experiments were done in the quiet of the scene and subjects took experiments alone without any external stimulus interference. In order to eliminate the influence of the measurement sequence, all subjects filled out the risk attitude questionnaire. Finally let the external network purchase situation decision. Before the start of the experiment, the main test descriptions refer to lead, to be tested that experimental procedures, the subjects received tips and strictly control the experiment.

\section{Results and analysis}

PANAS:

In PANAS, the emotion of subject was stale.

The effect of risk attitude on the network purchase decision

To describe the data statistical analysis, the mean risk attitude questionnaire is 108.84 , and standard deviation is 17.28. The score higher than the 126 is risk seeking, and less than 92 was for risk aversion and risk seeking was for the 45 , the risk neutral was for 201 and risk aversion was as 44 people. Make to buy USB decision of male students accounted for $37.7 \%$ of the total number of males, females accounted for $21.6 \%$ of the total number of females, and make a purchase clothes making males accounted for $51.9 \%$ of the total number of males, females accounted for $49.3 \%$ of the total number of females and 75 people choose to buy a USB flash drive and 145 people choose to buy clothes.

Table 1 The main effect of risk attitude

\begin{tabular}{ccccccccccc}
\hline \multirow{2}{*}{ item } & & \multicolumn{4}{c}{ clothes } & \multicolumn{5}{c}{ usb } \\
\cline { 3 - 9 } & & buy & $\begin{array}{c}\text { not } \\
\text { buy }\end{array}$ & $\chi^{2}$ & $P$ & buy & $\begin{array}{c}\text { not } \\
\text { buy }\end{array}$ & $\chi^{2}$ & $P$ \\
\hline Risk & risk seek & 31 & 14 & & & 30 & 15 & & \\
attitude & risk neutral & 104 & 97 & 19.757 & .000 & 36 & 165 & 46.377 & .000 \\
& $\begin{array}{l}\text { risk } \\
\text { aversion }\end{array}$ & 10 & 34 & & & 9 & 35 & & \\
\hline
\end{tabular}


As can be seen from the table, the main effect of risk attitude is significant, and the chi square test value is $19.757, \mathrm{df}=2, \mathrm{P}=0.000<0.001$. In the same case, the people who are more likely to seek risk make a purchase decision on clothes. The main effect of the risk attitude is significant, $\mathrm{df}=2, \mathrm{P}=$ $0.000<0.001$, in the same case, In the same case, the people who are more likely to seek risk make a purchase decision on usb and the people who are more likely to seek aversion don't make a purchase decision on usb and clothes.

\section{Discussion}

According to preliminary statistics analysis, under the same conditions, college students are more likely to make purchase decisions on clothes. Probably due to clothing is a necessity of life, students generally buying clothes risk bearing ability. In addition, according to existing survey, college students in the online purchase buying clothes the proportion was more than $80 \%$, indicating that for college students, network to buy the number of clothes occupy a large proportion, and university students on the network to buy clothes familiar is obviously higher than that of USB. Miao (2006) and interviews with college students online shopping experience results showed that students' perception of familiar for products is lower risk and may therefore are more likely to make a purchase decision.

Data results showed that risk attitude can affect the network purchase decisions, and people of risk seeking tend to make buying decisions. Risk attitude is a factor affecting online purchase decisions, and Chen, Ma (2012) and Lin and Ding (2010) concluded that the impact of consumer online behavior factors have individual risk attitude, and the significance of this conclusion is that people in online shopping activities, different risk attitudes should be more consideration to make inappropriate decisions because of their risk attitude.

This research also has many deficiencies. First, the selection of subjects did not involve professional and geographical for college students, and professional and geographical factors may affect the purchase decision-making. The age of college students is too single, and there are some errors; second, the experimental materials also exist to determine whether the self compiled online purchase scenarios, only according to the percentage to determine whether it can be used, although a certain risk attitude is the influence factors of online purchase decision.

\section{Conclusions}

The personal risk attitude significantly influenced the network purchasing decision. In the same case, the people who are more likely to seek risk make a purchase decision on usb and the people who are more likely to seek aversion don't make a purchase decision on usb and clothes.

\section{Acknowledgements}

The research work was supported by key discipline construction project (Cultivation project: public administration)of Shanghai Second Polytechnic University ( Grant No. XXKPY1307).

\section{References}

[1] Tan , S.J.(1999).Strategies for reducing consumers'risk aversion in Internet shopping.Journal of

Consumer Marketing.16(2),163-180.

[2] Jarvenpaa , S.L.(1999).N.Tractinsky,L.Saarinen,Consumer Trust in an Internet Store:a

Cross-cultural Validation.Joural of Computer Mediated Communication.5(2),1-35. 
Joan Chen. (2008) the influence factors of consumer purchasing decision in.C2C e-commerce mode. Shopping mall modernization, 163 - 530162

[3] Li Yuanzhi, Chen Hui. (2007) an analysis of the influence factors of consumers' purchase decision under the condition of electronic commerce. Journal of Beijing University of Posts and Telecommunications, $02,1-4$

[4] Ma Jiwei, Chen Yiwen. (2012) consumer purchase decision and its factors in electronic commerce. Psychological science progress, 20,27 - 34

[5] Guo Jianen. (2005) study on the process model of perceived risk and motivation of consumers in the online shopping context. Master's thesis of Zhejiang University.

[6] Li Juanjuan. (2008) consumers' perception of risk in different categories of products online shopping. 18,8586

[7] Lin Li, Ding Fu. (2010). Factors analysis of consumer purchase intention under the network environment. Chinese trading, 02,14 - 15

[8] Lin Zhenxu. Research on the influence of website characteristics and risk perception on consumers' online purchase intention. Master's thesis of Fudan University.

[9] Liu Dandan. (2011) the effect of risk attitude and time pressure on preference reversal in risk decision making. Shandong Normal University master's thesis.

[10] Liu Kan, Xie Jing, Zhuang Yulong. (2010) empirical study on the influencing factors of College Students' online shopping decision making. China business, 07,86 - 87

[11] Liu Zhe, Tong Lijun. (2011). The development of the theory and research methods of purchase decision. Economic management and scientific decision-making, 01144 - 145

[12]Yu Dan, Dong Dahai, Liu Ruiming, et al. (2007) research on risk sources, types and influencing factors of online shopping. Journal of Dalian University of Technology (SOCIAL SCIENCE EDITION), 28 (2), 13 - 19

[13] Li Juanjuan. (2008) consumers' perception of risk in different categories of products online shopping. Learning theory, 18,85 - 86

[14] Zhang Junjing. (2006) An Empirical Study on the factors affecting the consumer online shopping behavior. The dissertation of Fudan University. 